\title{
Adubação nitrogenada do arroz de terras altas no Sistema Plantio Direto
}

Cleber M. Guimarães ${ }^{1}$ \& Luís F. Stone ${ }^{2}$

\author{
1 EMBRAPA Arroz e Feijão. CP 179, CEP 75375-000, Santo Antônio de Goiás, GO. Fone: (62) 533-2178, Fax: (62) 533-2100. \\ E-mail: cleber@cnpaf.embrapa.br (Foto) \\ ${ }^{2}$ EMBRAPA Arroz e Feijão. Fone: (62) 533-2186. E-mail: stone@cnpaf.embrapa.br
}

Protocolo 146 - 7/10/2002 - Aprovado em 14/5/2003

\begin{abstract}
Resumo: Este trabalho objetivou determinar a dose e o modo de aplicação de nitrogênio (N) mais adequados para o arroz cultivado após pastagem ou soja, sob Sistema Plantio Direto (SPD). Os experimentos foram conduzidos em 1999/2000, em Santo Antônio de Goiás, GO, depois da pastagem de Brachiaria decumbens, e em Campo Verde, MT, após soja. Foi utilizado o delineamento de blocos casualizados, em esquema fatorial $5 \times 3$. Os tratamentos consistiram de cinco doses de $\mathrm{N}$ ( 12 ou 7, 40, 80, 120 e $160 \mathrm{~kg} \mathrm{ha}^{-1}$ ) combinadas com três modos de aplicação: totalmente na semeadura, metade na semeadura e metade na cobertura, e dois terços na semeadura e um terço na cobertura. A dose de $12 \mathrm{~kg}$ de $\mathrm{N} \mathrm{ha}^{-1}$ foi aplicada no experimento após pastagem que a de $7 \mathrm{~kg}$ de $\mathrm{N} \mathrm{ha}^{-1}$, em seguida à soja. $\mathrm{O}$ arroz apresentou maior resposta à adubação nitrogenada após pastagem e depois de soja. A resposta da produtividade do arroz ao $\mathrm{N}$ após pastagem, dependeu do modo de aplicação deste nutriente, sendo $100 \mathrm{~kg} \mathrm{ha}^{-1}$ a dose econômica de $\mathrm{N}$ para a aplicação total na semeadura. Em seguida à soja, o modo de aplicação não afetou a produtividade do arroz, sendo $68 \mathrm{~kg} \mathrm{ha}^{-1}$ a dose econômica de $\mathrm{N}$.
\end{abstract}

Palavras-chave: Oryza sativa, relação $\mathrm{C}: \mathrm{N}$, modo de aplicação do $\mathrm{N}$

\section{Nitrogen fertilization of upland rice under no-tillage system}

\begin{abstract}
The objective of this work was to determine the most adequate nitrogen (N) dose and the mode of its application for the upland rice grown after pasture or soybean, under no-tillage. The experiments were carried out during the 1999/2000 growing season, in Santo Antônio de Goiás, GO, after Brachiaria decumbens pasture, and in Campo Verde, MT, after soybean. A completely randomized block design was used, in a $5 \times 3$ factorial scheme. The treatments consisted of five doses of $\mathrm{N}$ (12 or $7,40,80,120$, and $160 \mathrm{~kg} \mathrm{ha}^{-1}$ ) combined with three modes of application: total at sowing, half at sowing and half top dressing, and two third at sowing and one third top dressing. $\mathrm{N}$ dose of $12 \mathrm{~kg} \mathrm{ha}^{-1}$ was applied in the first experiment and $\mathrm{N}$ dose of $7 \mathrm{~kg} \mathrm{ha}^{-1}$ in the second one. Rice showed higher response to $\mathrm{N}$ fertilization after pasture in comparison to soybean. Rice grain yield response to $\mathrm{N}$ after pasture depended on mode of application, $100 \mathrm{~kg} \mathrm{ha}^{-1}$ being the economic dose for total $\mathrm{N}$ application at sowing. Rice grain yield, following soybean was not affected by mode of application, under this condition, the economic dose of $\mathrm{N}$ was $68 \mathrm{~kg} \mathrm{ha}^{-1}$.
\end{abstract}

Key words: Oryza sativa, C:N ratio, $\mathrm{N}$ application form

\section{INTRODUÇÃO}

O Sistema Plantio Direto (SPD), que se caracteriza pela mobilização do solo apenas na linha de semeadura e na manutenção de palhada na superfície do solo, é uma opção viável para se alcançar a sustentabilidade da produção de arroz de terras altas na região do Cerrado, onde se situa a maioria da área cultivada com esta cultura. Na região, o SPD encontra-se implantado em mais de cinco milhões de hectares (Landers, 2001).
A maior consequiência da adoção desta prática é a alteração da dinâmica da matéria orgânica e da atividade biológica do solo, principalmente em decorrência da manutenção do solo coberto pela palhada. A taxa de decomposição dos resíduos é menor quando eles são mantidos na superfície do solo que quando incorporados (Bortoluzzi \& Eltz, 2000). Em solos sob SPD pode ocorrer menor disponibilidade de nitrogênio $(\mathrm{N})$ para as plantas, devido à maior imobilização microbiana deste nutriente (Kitur et al., 1984; Heinrichs et al., 2001). Kitur et al. (1984) verificaram que mais de $50 \%$ do $\mathrm{N}$ imobilizado se 
encontravam na camada superficial de $5 \mathrm{~cm}$, em que o teor de matéria orgânica e a atividade microbiana eram maiores, consumindo parte do $\mathrm{N}$ mineral que seria destinado à cultura. Entretanto, a população microbiana não se mantém crescendo indefinidamente, e a partir do momento em que o carbono $(\mathrm{C})$ facilmente oxidável desaparecer e o sistema em decomposição apresentar relação C:N menor que 25:1, começará a ocorrer liberação de N para as plantas (Sá, 1999).

No sistema convencional de preparo do solo, a recomendação atual de adubação nitrogenada para o arroz de terras altas varia de 15 a $60 \mathrm{~kg}$ de $\mathrm{N} \mathrm{ha}^{-1}$ (Fageria, 1998; Stone \& Silva, 1998) e, no SPD, de 40 a $90 \mathrm{~kg}$ de $\mathrm{N} \mathrm{ha}^{-1}$ (Fageria, 1998) dependendo da suscetibilidade da cultivar ao acamamento e à brusone. Entretanto, como a magnitude em que a imobilização afeta a disponibilidade do $\mathrm{N}$ depende da relação $\mathrm{C}: \mathrm{N}$, da composição e da quantidade de resíduos produzidos pela cultura anterior, a resposta do arroz de terras altas à adubação nitrogenada no SPD deverá ser diferente após uma leguminosa ou uma gramínea.

Considerando-se que, na região do Cerrado, a cultura do arroz de terras altas no SPD é conduzida principalmente após soja ou pastagem objetivou-se, com este trabalho, determinar as doses e os modos de aplicação de $\mathrm{N}$ mais adequados para essas condições.

\section{MATERIAL E MÉTODOS}

Os experimentos foram conduzidos em SPD, após pastagem de Brachiaria decumbens, na Fazenda Alto da Glória, município de Santo Antônio de Goiás, GO, e após soja, na Fazenda Cristalina, município de Campo Verde, MT, no ano agrícola 1999/2000. A análise química inicial dos solos na camada de 0$20 \mathrm{~cm}$ de profundidade, apresentou os seguintes resultados: $\mathrm{pH}\left(\mathrm{H}_{2} \mathrm{O}\right) 5,4$ e 5,$6 ; \mathrm{Ca}^{2+}+\mathrm{Mg}^{2+} 1,3$ e $3,6 \mathrm{cmol}_{\mathrm{c}} \mathrm{dm}^{-3} ; \mathrm{Al}^{3+} 0,3$ e 0,1 $\mathrm{cmol}_{\mathrm{c}} \mathrm{dm}^{-3}$; P 0,9 e 18,7 $\mathrm{mg} \mathrm{dm}^{-3}$; K 67 e $53 \mathrm{mg} \mathrm{dm}^{-3}$; Cu 1,4 e 2,3 $\mathrm{mg} \mathrm{dm}^{-3}$; Zn 0,7 e 8,6 mg dm${ }^{-3}$; Fe 132 e $69 \mathrm{mg} \mathrm{dm}^{-3}$, Mn 42 e 10 $\mathrm{mg} \mathrm{dm}{ }^{-3}$ e M.O. 20 e $21 \mathrm{~g} \mathrm{~kg}^{-1}$, respectivamente, nas Fazendas Alto da Glória e Cristalina. A primeira propriedade adotou, durante vários anos, uma monocultura de pastagem na área usada para a instalação do experimento, enquanto a segunda propriedade adotou a monocultura de soja no período de verão, e milheto, sorgo ou milho na safrinha. Foi utilizado o delineamento de blocos casualizados, em esquema fatorial $5 \times 3$, com três repetições no experimento após pastagem e com quatro no após soja. Os tratamentos consistiram da combinação de cinco doses de $\mathrm{N}$ ( 12 ou 7, 40, 80, 120 e $160 \mathrm{~kg} \mathrm{ha}^{-1}$ ) com três modos de aplicação: totalmente na semeadura, metade na semeadura e metade na cobertura, e dois terços na semeadura e um terço em cobertura. A aplicação em cobertura foi feita por ocasião do início da diferenciação floral. A dose de $12 \mathrm{~kg} \mathrm{ha}^{-1}$ de $\mathrm{N}$ foi aplicada no experimento após pastagem, e a de $7 \mathrm{~kg} \mathrm{ha}^{-}$ ${ }^{1}$ de $\mathrm{N}$, no experimento após soja. O tamanho das parcelas foi de 4 × 30 m e de 4 x 40 m, respectivamente, nos experimentos após pastagem e após soja. O fósforo, o potássio, e a menor dose de $\mathrm{N}$ (12 ou $7 \mathrm{~kg} \mathrm{ha}^{-1}$ ) foram aplicados na semeadura, utilizando-se $300 \mathrm{~kg} \mathrm{ha}^{-1}$ da fórmula 4-30-16, no experimento após pastagem, e $350 \mathrm{~kg} \mathrm{ha}^{-1}$ da fórmula 2-18-18, no após soja. Para completar as demais doses estabelecidas de N, aplicaram- se quantidades adequadas de sulfato de amônio na superfície do solo imediatamente após a semeadura. No experimento após pastagem, foi aplicada na superfície do solo $1,7 \mathrm{t} \mathrm{ha}^{-1}$ de calcário com PRNT de $75 \%$, para neutralização do Al trocável e elevação de $\mathrm{Ca}$ e $\mathrm{Mg}$. Em ambos os experimentos aplicaram-se $20 \mathrm{~kg} \mathrm{ha}^{-1}$ de sulfato de zinco e $20 \mathrm{~kg} \mathrm{ha}^{-1}$ de FTE BR 12. Utilizou-se a cultivar de arroz Primavera no experimento após pastagem e a Canastra no após soja, semeadas no espaçamento de $40 \mathrm{~cm}$ entre linhas, com 70 sementes por metro. As sementes foram tratadas com carboxin + thiran $(110 \mathrm{~mL}$ i.a. por $100 \mathrm{~kg}$ semente $)$ e carbofuran (525 g i.a. por $100 \mathrm{~kg}$ semente). O experimento após soja recebeu pulverização preventiva com benomyl (500 g i.a. ha ${ }^{-1}$ ) contra brusone, na fase de emissão de panículas.

Avaliaram-se a produtividade e seus componentes. Os dados obtidos foram submetidos às análises de variância e de regressão. Foi também calculada a dose máxima econômica, igualando a derivada primeira da função de produção, determinada por meio da equação de regressão, à relação de preços do $\mathrm{N}$ e do arroz. Consideraram-se os preços vigentes na praça de Goiânia, em agosto/2002, para o N, na forma de sulfato de amônio, e para o arroz, R\$1,85 kg-1 e R\$ 0,42 $\mathrm{kg}^{-1}$, respectivamente.

\section{RESULTADOS E DISCUSSÃO}

No experimento após pastagem, a interação entre o modo de aplicação e dose de $\mathrm{N}$ foi significativa apenas para a produtividade (Tabela 1). A resposta da produtividade do arroz à adubação nitrogenada, em todos os modos de aplicação, foi explicada por equações quadráticas (Figura 1). Quando o N foi aplicado totalmente na semeadura, a produtividade aumentou até a dose de $118 \mathrm{~kg} \mathrm{ha}^{-1}$, apresentando o valor de $2754 \mathrm{~kg} \mathrm{ha}^{-1}$, superior em $153 \%$ à produtividade estimada no tratamento sem aplicação de N. Entretanto, quando as doses de $\mathrm{N}$ foram parceladas, não se observou ponto de máximo físico da produtividade, dentro da amplitude de variabilidade das doses de $\mathrm{N}$ usadas. Quando da aplicação total na semeadura, a dose de adubação nitrogenada que propiciou a máxima eficiência econômica foi $100 \mathrm{~kg} \mathrm{ha}^{-1}$, para uma produtividade de $2713 \mathrm{~kg} \mathrm{ha}^{-1}$, situando-se pouco acima do limite superior da faixa de recomendação de Fageria (1998) para o SPD e acima da faixa de valores recomendados para o sistema convencional de preparo do solo (Fageria, 1998; Stone \& Silva, 1998).

Ehlers \& Claupein (1992) observaram que nos anos iniciais do SPD, foi necessário aplicar-se mais N para atingir os níveis de produtividade do sistema convencional de preparo do solo, devido à maior demanda de $\mathrm{N}$ na fase de implantação da cultura no SPD, em função da imobilização microbiana do nitrogênio (Kitur et al., 1984; Heinrichs et al., 2001). Entretando, após alguns anos do SPD, com adubações extras de $\mathrm{N}$ ou com a introdução de leguminosas no sistema, a demanda e a eficiência da adubação nitrogenada nos dois sistemas se aproximavam.

$\mathrm{O}$ aumento da produtividade com o incremento da dose de $\mathrm{N}$ pode ser explicado pelo crescimento no número de panículas por $\mathrm{m}^{2}$, que apresentou resposta quadrática segundo a equação $\mathrm{Y}=92,9+1,187 \mathrm{X}-0,0039 \mathrm{X}^{2}, \mathrm{R}^{2}=0,99$, com ponto de máximo 
Tabela 1. Resumo da análise de variância da produtividade do arroz de terras altas e seus componentes, sob Sistema Plantio Direto após pastagem

\begin{tabular}{|c|c|c|c|c|c|c|}
\hline \multirow{2}{*}{$\begin{array}{l}\text { Fonte de } \\
\text { Variação }\end{array}$} & \multirow[b]{2}{*}{ G.L. } & \multicolumn{5}{|c|}{ Quadrado Médio } \\
\hline & & $\begin{array}{l}\text { Produtividade } \\
\qquad\left(\mathrm{kg} \mathrm{ha}^{-1}\right)\end{array}$ & $\begin{array}{l}\text { Panículas } \\
\left(\mathrm{n}^{\circ} \mathrm{m}^{-2}\right)\end{array}$ & $\begin{array}{c}\text { Grãos por } \\
\text { Panícula }\left(\mathrm{n}^{\circ}\right)\end{array}$ & $\begin{array}{c}\text { Massa de } \\
100 \text { Grãos (g) }\end{array}$ & $\begin{array}{l}\text { Esterilidade de } \\
\text { Espiguetas (\%) }\end{array}$ \\
\hline Bloco & 2 & $375237,8 * *$ & $307,4 \mathrm{~ns}$ & $49,5 \mathrm{~ns}$ & $0,022 \mathrm{~ns}$ & $28,43 *$ \\
\hline Dose de $N(N)$ & 4 & $3276394,8 * *$ & $9616,8 * *$ & $1412,6 * *$ & $0,095 * *$ & $99,27 * *$ \\
\hline $\mathrm{N}$ linear & (1) & $11975654,4 * *$ & $35984,0 * *$ & $5005,4 * *$ & $0,342 * *$ & $294,99 * *$ \\
\hline $\mathrm{N}$ quadrático & (1) & $587803,5^{* *}$ & $2402,5^{*}$ & $109,2 \mathrm{~ns}$ & $0,033 *$ & $13,15 \mathrm{~ns}$ \\
\hline C.V. (\%) & & 4,99 & 14,36 & 6,71 & 3,74 & 13,92 \\
\hline
\end{tabular}

ns: F não-significativo a 5\%; *: F significativo a 5\%; **: F significativo a $1 \%$

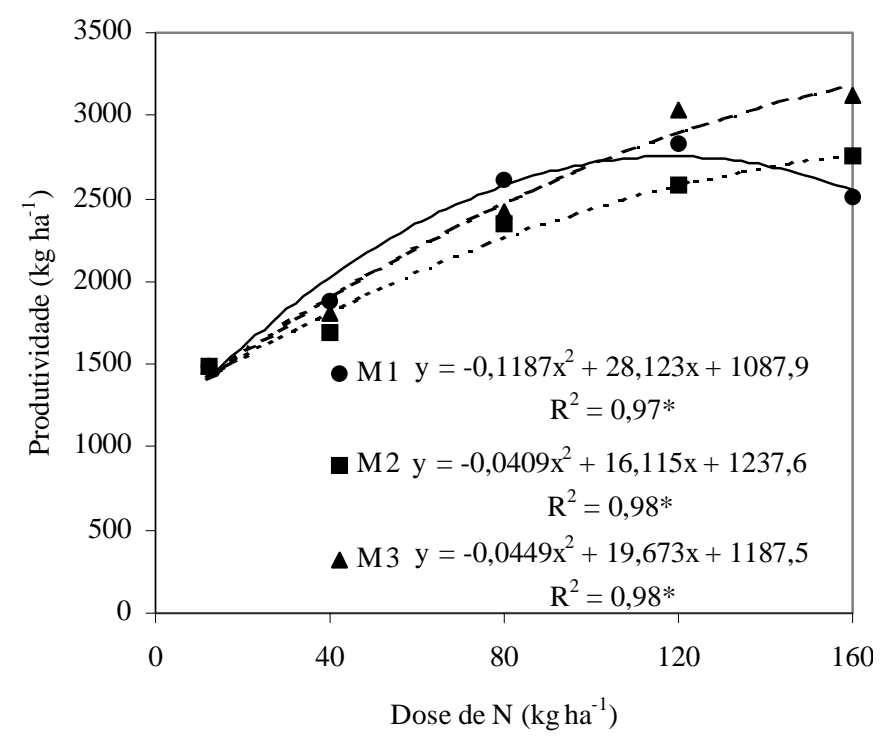

Figura 1. Produtividade do arroz de terras altas sob Sistema Plantio Direto após pastagem, em função de doses de $\mathrm{N}$ aplicadas totalmente na semeadura (M1), metade na semeadura e metade na cobertura (M2) e dois terços na semeadura e um terço em cobertura (M3)

igual a $152 \mathrm{~kg} \mathrm{ha}^{-1}$ de $\mathrm{N}$, e pelo aumento no número de grãos por panícula, que apresentou resposta linear segundo a equação $\mathrm{Y}=101,7+0,201 \mathrm{X}, \mathrm{R}^{2}=0,92$ (Tabela 1$)$.

A massa de 100 grãos diminuiu com o aumento da dose de $\mathrm{N}$, segundo a equação quadrática $\mathrm{Y}=2,38+0,0001 \mathrm{X}-0,00001 \mathrm{X}^{2}$, $\mathrm{R}^{2}=0,98$, observando-se maior redução a partir da dose de 80 $\mathrm{kg} \mathrm{ha}^{-1}$ de N. A esterilidade de espiguetas apresentou resposta linear positiva às doses de $\mathrm{N}$, conforme a equação $\mathrm{Y}=16,8+$ $0,048 \mathrm{X}, \mathrm{R}^{2}=0,74$ (Tabela 1) em razão da maior ocorrência de brusone nas panículas. As infecções ocasionadas pela doença geralmente ocorrem no primeiro nó abaixo da panícula, necrosando os tecidos e estrangulando o fluxo de carboidratos, o que compromete o enchimento dos grãos (Prabhu et al., 1986). $\mathrm{O} \mathrm{N}$ em doses elevadas intensifica a severidade da brusone (Santos et al., 1986). Os autores afirmam, também, que a aplicação da totalidade do $\mathrm{N}$ no sulco por ocasião da semeadura aumenta a severidade da brusone quando comparada com a aplicação parcelada, porém neste trabalho se constatou que a aplicação de todo o $\mathrm{N}$ na semeadura resultou em menor severidade da doença, comparativamente com as aplicações parceladas na semeadura e em cobertura, causando menor esterilidade de espiguetas, $18,2 \%$, em relação aos outros modos de aplicação, 22,5 e 21,4\%, respectivamente.

A maior imobilização microbiana de $\mathrm{N}$ em solos com resíduos de alta relação $\mathrm{C}: \mathrm{N}$ na superfície, como na área de SPD após pastagem de Brachiaria, C:N $\geq 70$ (Rezende et al., 1999) pode ter contribuído para a redução na esterilidade de espiguetas, uma vez que a reciclagem de nutrientes é mais vagarosa (Fernandes et al., 1999); este fato pode explicar a menor ocorrência de brusone quando a adubação nitrogenada foi aplicada totalmente na semeadura. Apesar disto, o modo de aplicação foi menos eficiente para o enchimento dos grãos, resultando em massa média de 100 grãos de $2,21 \mathrm{~g}$, inferior às obtidas nos tratamentos com parcelamento, metade na semeadura e matade na cobertura e dois terços na semeadura e um terço na cobertura. Assim, o maior número de grãos por panícula obtido neste tratamento com as maiores doses de $\mathrm{N}$, não compensou a redução na massa dos grãos, ocorrendo queda na produtividade, nessas doses.

$\mathrm{O}$ arroz cultivado após soja apresentou índices de produtividade mais altos que o após pastagem; entretanto, respondeu com menor intensidade à adubação nitrogenada. Para esta condição, a produtividade e seus componentes, com exceção da massa de 100 grãos, só apresentaram resposta significativa às doses de $\mathrm{N}$ (Tabela 2 ). A produtividade média máxima foi de aproximadamente $3441 \mathrm{~kg} \mathrm{ha}^{-1}$, para uma dose de $107 \mathrm{~kg} \mathrm{ha}^{-1} \mathrm{de}$ $\mathrm{N}$ (Figura 2) um aumento de produtividade de apenas $23 \% \mathrm{em}$ relação à estimada para a dose zero de $\mathrm{N}$. O máximo econômico foi de $68 \mathrm{~kg} \mathrm{ha}^{-1}$ de $\mathrm{N}$ para uma produtividade de $3353 \mathrm{~kg} \mathrm{ha}^{-1}$, situando-se aproximadamente no meio da faixa de recomendação proposta por Fageria (1998) para o SPD. Neste experimento, a demanda por $\mathrm{N}$ foi menor em virtude do cultivo ter sido conduzido em área de soja, em que ocorre maior mineralização do nitrogênio. Segundo Wienhold \& Halvorson (1999) o aumento na taxa de mineralização de $\mathrm{N}$ representa, também, aumento do estoque deste nutriente no solo na fórmula orgânica lábil. Solos com grande estoque de $\mathrm{N}$ lábil são capazes de suprir a maior parte da demanda da planta por N. Além do mais, este $\mathrm{N}$ não se perde por lixiviação, o que explica o bom efeito da adubação aplicada totalmente na semeadura.

O crescimento da produtividade com o incremento da dose de $\mathrm{N}$ pode ser explicado pelo aumento no número de panículas 
Tabela 2. Resumo da análise de variância da produtividade do arroz de terras altas e seus componentes, sob Sistema Plantio Direto, após soja

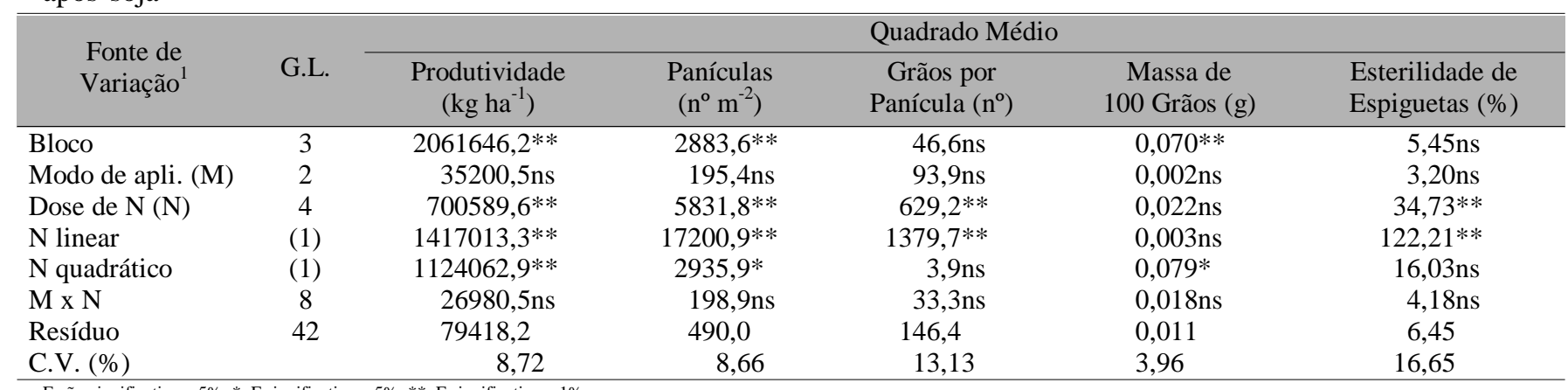

ns: F não-significativo a 5\%; *: F significativo a 5\%; **: F significativo a $1 \%$

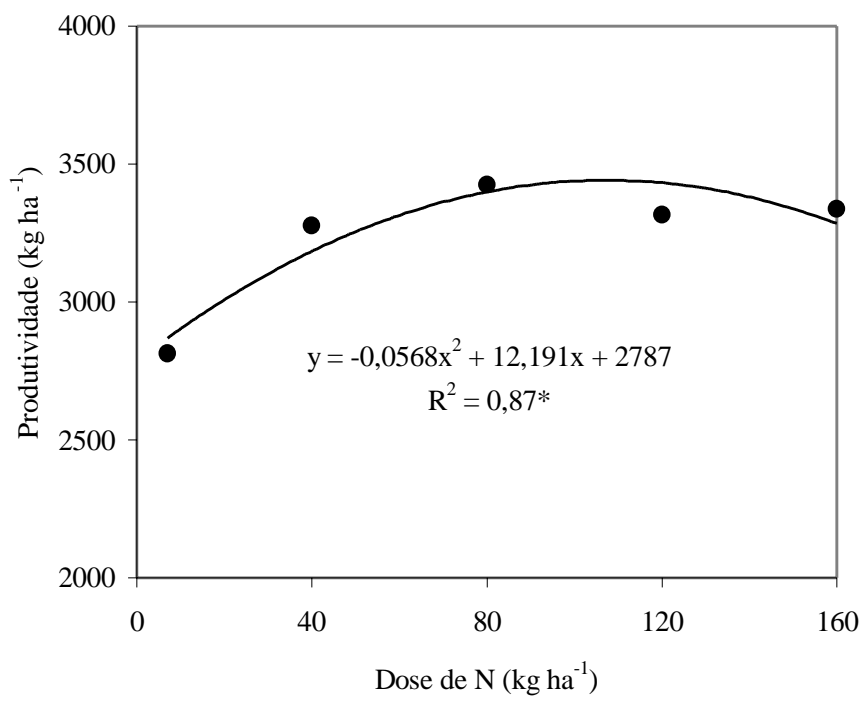

Figura 2. Produtividade do arroz de terras altas sob Sistema Plantio Direto após soja, em função de doses de N

por $\mathrm{m}^{2}$, que apresentou resposta quadrática segundo a equação $\mathrm{Y}=218,1+0,829 \mathrm{X}-0,0031 \mathrm{X}^{2}, \mathrm{R}^{2}=0,87$ (Tabela 2 ) com ponto de máximo igual a $134 \mathrm{~kg} \mathrm{ha}^{-1} \mathrm{de} \mathrm{N}$.

O número de grãos por panícula, ao contrário do observado após pastagem, diminuiu linearmente com o aumento da dose de $N$, segundo a equação $Y=99,3-0,088 X, R^{2}=0,55$. Como a cultivar usada neste experimento perfilhou bem mais que a usada no experimento após pastagem, o que se refletiu no maior número de panículas por $\mathrm{m}^{2}$, esta redução está relacionada à maior competição entre plantas, com o aumento da dose de N. Santos et al. (1986) e Stone \& Pereira (1994) também observaram redução no número de grãos por panícula, com o aumento do número de panículas por $\mathrm{m}^{2}$.

O Sistema de Plantio Direto de arroz após soja, apesar de mais propenso ao ataque de brusone devido aos resíduos apresentarem baixa relação C:N, 16 a 23 (Gilmour et al., 1998) comparativamente ao ambiente após pastagem, apresentou menor índice de esterilidade de espiguetas em virtude, provavelmente, de pulverizações preventivas contra esta doença; contudo, não impediu o aumento da esterilidade de espiguetas com o aumento das doses de $\mathrm{N}$, segundo a equação linear $\mathrm{Y}=13,1+0,0264 \mathrm{X}, \mathrm{R}^{2}=0,90$ (Tabela 2).

A menor ocorrência de brusone, especialmente com as menores doses de $\mathrm{N}$, fez com que, ao contrário do observado no experimento após pastagem, a massa de 100 grãos só decrescesse a partir da dose de $90 \mathrm{~kg} \mathrm{ha}^{-1}$ de $\mathrm{N}$, conforme a equação $Y=2,63+0,0026 X-0,0000144 X^{2}, R^{2}=0,92$.

\section{CONCLUSÕES}

1. O arroz de terras altas sob Sistema de Plantio Direto apresenta maior resposta à adubação nitrogenada após pastagem que após soja.

2. A resposta ao $\mathrm{N}$ da produtividade do arroz de terras altas sob Sistema de Plantio Direto após pastagem, depende do modo de aplicação deste nutriente.

3. O modo de aplicação do N não afeta a produtividade do arroz de terras altas sob Sistema de Plantio Direto, após soja.

4. Após soja, a dose de $\mathrm{N}$ que propicia a máxima eficiência econômica é de $68 \mathrm{~kg} \mathrm{ha}^{-1}$ e, após pastagem, para a aplicação total na semeadura, é de $100 \mathrm{~kg} \mathrm{ha}^{-1}$.

\section{LITERATURA CITADA}

Bortoluzzi, E.C.; Eltz, F.L.F. Efeito do manejo mecânico da palhada de aveia preta sobre a cobertura, temperatura, teor de água no solo e emergência da soja em sistema plantio direto. Revista Brasileira de Ciência do Solo, Viçosa, v.24, n.2, p.449-457, 2000.

Ehlers, W.; Claupein, W. Approaches toward conservation tillage in Germany. In. Carte, M.R. (ed.). Conservation tillage in temperate agroecosystems. Boca Rotan: Lewis Publishers, 1992.p.141-165.

Fageria, N.K. Manejo da calagem e da adubação do arroz. In: Breseghello, F.; Stone, L.F. (eds.). Tecnologia para o arroz de terras altas. Santo Antônio de Goiás: EMBRAPA Arroz e Feijão, 1998. p.67-78.

Fernandes, L.A.; Nascente, C.M.; Silva, M.L.N.; Furtini Neto, A.E.; Vasconcelos, C.A. Sistemas de preparo do solo e adubação nitrogenada na produtividade do milho em Latossolo Vermelho escuro fase cerrado. Revista Plantio Direto, Passo Fundo, v.51, p.15-16, 1999.

Gilmour, J.T.; Mauromoustakos, A.; Gale, P.M.; Norman, R.J. Kinetics of crop residue decomposition: variability among crops and years. Soil Science Society of America Journal, Madison, v.62, n.3, p.750-755, 1998.

Heinrichs, R.; Aita, C.; Amado, T.J.C.; Fancelli, A.L. Cultivo consorciado de aveia e ervilhaça: relação $\mathrm{C} / \mathrm{N}$ da fitomassa e produtividade do milho em sucessão. Revista Brasileira de Ciência do Solo, Viçosa, v.25, n.2, p.331-340, 2001. 
Kitur, B.K.; Smith, M.S.; Blevins, R.L.; Frye, W.W. Fate of ${ }^{15} \mathrm{~N}$ depleted ammonium nitrate applied to no-tillage and conventional tillage corn. Agronomy Journal, Madison, v.76, p.240-242, 1984.

Landers, J.N. Clubes amigos da terra na disseminação e desenvolvimento do plantio direto no Brasil tropical. In: Encontro Regional de Plantio Direto no Cerrado, 5, 2001, Dourados. Sustentabilidade, sim!: Anais... Brasília: APDC/Dourados: UFMS: EMBRAPA Agropecuária Oeste, 2001. p.64-68.

Prabhu, A.S.; Faria, J.C. de; Carvalho, J.R.P. de. Efeito da brusone sobre a matéria seca, produção de grãos e seus componentes, em arroz de sequeiro. Pesquisa Agropecuária Brasileira, Brasília, v.21, n.5, p.495-500, 1986.

Rezende, C.D.; Cantarutti, R.B.; Braga, J.M.; Gomide, J.A.; Pereira, J.M.; Ferreira, E.; Tarre, R.; Macedo, R.; Alves, B.J.R.; Urguiaga, S.; Cadisch, G.; Giller, K.E.; Boddey, R.M. Litter deposition and disappearance in Brachiaria pastures in the Atlantic forest region of the South of Bahia, Brazil. Nutrient Cycling in Agroecosystems, Dordrecht, v.54, n.2, p.99-112, 1999.
Sá, J.C. de M. Manejo da fertilidade do solo no sistema plantio direto. In: Inter-relação fertilidade, biologia do solo e nutrição de plantas. Viçosa: SBSC/Lavras: UFLA/DCS, 1999. p.291309.

Santos, A.B. dos; Prabhu, A.S.; Aquino, A.R.L. de; Carvalho, J.R.P. de. Épocas, modos de aplicação e níveis de nitrogênio sobre brusone e produção de arroz de sequeiro. Pesquisa Agropecuária Brasileira, Brasília, v.21, n.7, p.697-707, 1986.

Stone, L.F.; Pereira, A.L. Sucessão arroz-feijão irrigados por aspersão: efeitos de espaçamento entre linhas, adubação e cultivar na produtividade e nutrição do arroz. Pesquisa Agropecuária Brasileira, Brasília, v.29, n.11, p.1701-1713, 1994.

Stone, L.F.; Silva, J.G. da. Resposta do arroz de sequeiro à profundidade de aração, adubação nitrogenada e condições hídricas do solo. Pesquisa Agropecuária Brasileira, Brasília, v.33, n.6, p.891-897, 1998 .

Wienhold, B.J.; Halvorson, A.D. Nitrogen mineralization responses to cropping, tillage, and nitrogen rate in the Northern Great Plains. Soil Science Society of America Journal, Madison, v.63, p.192-196, 1999. 